\title{
Percepcija uloge uspavanke u razvoju deteta predškolskog uzrasta iz ugla vaspitača
}

\author{
Snežana Marinković \\ Univerzitet u Kragujevcu \\ marinkovic@pfu.kg.ac.rs
}

Daliborka Purić

Univerzitet u Kragujevcu

daliborka.puric@gmail.com

\section{Ljiljana Kostić \\ Univerzitet u Kragujevcu \\ ljkostic972@gmail.com}

\begin{abstract}
Uspavanka kao sadržaj vaspitnoobrazovnih aktivnosti na predškolskom nivou može biti faktor lingvističkog, kognitivnog, socioemocionalnog razvoja deteta. Imajući u vidu višestruku funkcionalnost ove književne forme u kontekstu različitih aspekata razvoja ličnosti deteta, sa jedne, i njegovih razvojnih osobenosti, sa druge strane, autori u radu ispituju mišljenje vaspitača $(N=302)$ u vezi sa (a) ulogom uspavanke u aktivnostima sa decom predškolskog uzrasta; (b) primerenošću primene uspavanke različitim predškolskim uzrasnim grupama dece. Rezultati istraživanja pokazuju da vaspitači prepoznaju značaj uspavanke u funkciji socioemocionalnog razvoja, uspavljivanja, razvoja govora i jezičkog stvaralaštva, saznajnog razvoja, unapređivanja muzičkih sposobnosti, negovanja tradicije i razvijanja interkulturalnosti, ističući da je najprimerenija u radu sa decom od 3 do 4 godine. Razumevanje značaja ove književne vrste u funkciji ostvarivanja vaspitnoobrazovnih ciljeva zasnovanih na vrednosnim postulatima detinjstva i deteta, od strane vaspitača kao koordinatora aktivnosti na predškolskom nivou, doprinosi obezbeđivanju kvalitetnog okruženja za rani razvoj i učenje.
\end{abstract}

Ključne reči: uspavanka, vaspitač, dete predškolskog uzrasta, emocionalni razvoj, socijalni razvoj

\section{Uvod}

Uzrasni period od rođenja do polaska u školu, tokom koga se odvija intenzivni psiho-fizički razvoj, otvara brojne mogućnosti ovladavanja i razvijanja složenih kapaciteta deteta, od čijeg kvaliteta umnogome zavisi razvoj njegove ličnosti. Pored porodice, značajnu ulogu u tom procesu ima vaspitač, 
kao koordinator aktivnosti i odnosa između vaspitne grupe, predškolske ustanove i mikro i makrookruženja, kroz čiju se dinamičnu spregu odvija predškolsko vaspitanje i obrazovanje. Kompleksnost, promenljivost i nepredvidivost razvoja deteta u ovom periodu rezultira stalnim suočavanjem vaspitača sa novim izazovima, koje treba da rešava u skladu sa svojim uverenjima, znanjima i umenjima, kroz refleksivno preispitivanje teorije i prakse u odnosu na dati kontekst. Tom prilikom, u cilju podrške dobrobiti deteta, vaspitači ispoljavaju svoju autonomiju, kreativnost i profesionalnost, kao i proaktivno zastupanje interesa dece i porodice (Pravilnik o osnovama programa predškolskog vaspitanja i obrazovanja 2018).

Program predškolskog vaspitanja i obrazovanja, između ostalog, treba da omogući deci da upoznaju, istražuju i preispituju različita područja ljudskog saznanja i delanja, različite produkte kulture i načine građenja i izražavanja značenja. Književna umetnost predstavlja jedan od elemenata sadržaja, posredstvom koga se ostvaruju zahtevi predškolskog vaspitanja i obrazovanja. Cilj ovog rada jeste da se razmotri značaj uspavanki, kao kulturološki posredovanog književno-umetničkog sadržaja, u funkciji ostvarivanja vaspitnoobrazovnih ciljeva zasnovanih na teorijsko-vrednosnim postulatima detinjstva i deteta.

\section{Teorijske osnove}

Uspavanke su prve pesme koje se kazuju/pevaju deci, nastale s ciljem da im obezbede miran san $i$, istovremeno, sačuvaju ih od zlih sila i osiguraju dug i zdrav život (Prstojević 2012, 64). One su »iskaz ljubavi, nežnosti i milošte« (up. Krnjević 1992, 907), koji se odlikuje lirskom neposrednošću, toplinom, slikovitošću i naglašenom emotivnošću. $U$ njima dete dobija "preobilje nežnosti, bar koliko jezik može poneti« (Šarančić Čutura 2017, 42), što potvrđuju veoma ekspresivne metafore koje svedoče o neobičnom rođenju deteta (»Majka Jovu u ruži rodila«, »Majka Smilju u želji rodila«) i o dragocenosti koju ono predstavlja za majku (ili drugog bliskog izvođača): »Ne bud'te mi sina moga, / ne bud'te mi hranu moju. [...] Zaspi mi, sine, zaspi mi sunce, / grejaćeš majku.« (Čalenić 1972, 13)

Trenutak uspavljivanja bio je i »trenutak smirenja i predaha od dnevne vreve« i za izvođača uspavanke, a, takođe, i »prilika da iskažu neke vlastite, patrijarhalnim normama potisnute želje i slutnje« (Pešikan Ljuštanović 2012b). Kontekst u kome se ove pesme izvode (dete se uspavljuje u kolevci ili »ninajući« u naručju ili na krilu) obezbeđuje prisan odnos između majke ili one osobe koja izvodi uspavanke i deteta.

Kao prvi stihovi koji se kazuju/pevaju deci, uspavanke su veoma pogodne 
za izgradnju emocionalne bliskosti, budući da se sa detetom na ranom uzrastu još uvek ne mogu voditi stvarni razgovori (Hüsler 2011, 11). Prisustvo majke ili neke druge osobe (ranije babe i sestre, u novijim autorskim uspavankama i oca), njen/njegov tihi glas i osobeni ritam ovih pesama dovoljni su da se dete umiri i prevaziđe strah, nelagodnost i stanje nemira i napetosti (Noll 2012, 19). Prisustvo roditelja "povezano je sa fizičkom zaštitom, ali se može tumačiti i kao vid psihološke zaštite« (Košprdić i Damjanov 2017, 79), posebno u vezi sa dečjim strahom od mraka, samoće i napuštenosti. Uspavanke, stoga, ostavljaju utisak da su majka ili osoba koja izgovara/peva uspavanku uvek prisutni, što omogućuje deci da se osećaju sigurno (»Spavaj, bebo, ti / mama će te čuvati«).

Specifična sadržina uspavanki, zasnovana na osobenoj leksici (deminutivi i onomatopeične reči), potom slikovitost, ritmičnost i melodičnost stvaraju opuštajuću atmosferu. Sugestivnost ovih pesama pojačana je neodvojivom povezanošću zvuka koji reči imaju i njihovog značenja. Fonološke jedinice u književnom delu mogu »da uspostavljaju dopunske veze među rečima« i da budu nosioci značenja, što često nije slučaj u svakodnevnom govoru (Lotman 1976, 157-158). U uspavankama se jasno uočava logički i stilistički sklad među fonemama i rečima koje one tvore (Antoš 1974, 35). Učestalost vokala $a$ i vokala srednjeg reda $i$ - »Ninaj, ninaj, zlato moje«, »Nini, sine, san te prevario« stvara osećaj »tananosti, jasnosti i finoće." (Lešić 2011, 94) Prisustvo bezvučnih $(k, t, \breve{s}, s)$ i zvučnih suglasnika $(j, l, l j, n, n j)$ u specifičnim kombinacijama sa dugim i kratkim vokalima - »Iš, kokote, šaradane«, »Ljulja, ljulja, ljuška«, »Oj, sokole, moj sokole« - ima izrazito eufonični karakter (Lešić 2011, 94). Dominacijom zvučnih figura (asonanca, aliteracija i onomatopeja) i lirskih paralelizama (anafora, epifora, poliptoton, paronomazija) pojačava se sugestivnost, ritmičnost, melodičnost i »efekat hipnoze« (Živković 2019, 607). Aliteracije $s i$ š sugerišu smirivanje i opuštanje deteta: »ľs, paune, šaropere, / ne šetukaj, ne babukaj, / ne šoboći.« (Čalenić 1972, 13) Onomatopeične reči (buji, paji, ljulju ljuška, ninaj, nanaj i sl.), kojima uspavanke najčešće počinju, doprinose ritamskoj organizaciji pesme. Preovlađujuća trohejska ritamska organizacija bliska je deci i povoljno utiče na njegov rani rast i razvoj. »Deca celog sveta skaču $i$ plešu u ritmu troheja; možda zato što sve majke svojim bebama koje još ne govore usađuju taj ritam dok ih ljuljaju, bacaju u vis, plješću dlanovima ili pevaju uspavanke.« (Čukovski 1986, 284) Nežni i tihi glas onih koji kazuju/pevaju uspavanke doprinose »smirenju, kontrolisanju emocija i boljem funkcionisanju metabolizma«, te jačanju osećaja sigurnosti i zaštićenosti (Vlainić i Jovančević 2009, 26).

Uspostavljanje komunikacije (verbalne i neverbalne) na relaciji majka - 
dete, otac - dete ili vaspitač - dete preduslov su i za socioemocionalni razvoj deteta, što uz kontakt koji pritom postoji između njih (sedenje u krilu, držanje u naručju, zagrljaj, držanje za ruku, kontakt očima) pojačava osećaj emocionalne sigurnosti deteta i njegovo samopouzdanje i samopoštovanje (Güneş i Güneş 2012, 317). To nadalje doprinosi podsticanju bliskosti između deteta i vaspitača i stvaranju prijatne, porodične atmosfere u grupi, »čime se olakšava period adaptacije, najčešće u radu sa jaslenom i mlađom grupom« (Purić i Kostić 2019, 362).

Navedeni aspekti višestruke funkcionalnosti uspavanke u kontekstu emocionalnog, socijalnog i saznajnog razvoja omogućuju metodičku integraciju različitih predmetnih oblasti i ostvarivanje ciljeva predškolskog vaspitanja i obrazovanja, zasnovanih na vrednosnim postulatima detinjstva i deteta kao jedinstvenog bića: (a) čiji je intelektualni, emocionalni, senzo-motorni, socijalni i govorni razvoj uzajamno uslovljen i isprepleten; (b) čiji se potencijali i razvijajući kapaciteti izgrađuju kroz interpersonalne odnose sa odraslima i vršnjacima; (c) čije je fizičko, emocionalno, socijalno, jezičko, čulno, kognitivno učenje uzajamno povezano i odvija se simultano; (d) koje ima kreativni potencijal da povezuje različite dimenzije svog iskustva i prerađuje svoje ideje i doživljaje; (e) koje potencijal otvorenosti, fleksibilnosti i stvaralaštva razvija kroz igru (»Osnove programa predškolskog vaspitanja i obrazovanja«, 2018).

Emocionalni, socijalni i saznajni razvoj, prema periodizacijama psihičkog razvoja, od rođenja do polaska u školu odvijaju se kroz tri razvojna perioda: (1) period novorođenčeta i odojčeta - od rođenja do kraja prve godine; (2) prvo detinjstvo - od kraja prve, do kraja druge-treće godine; (3) rano detinjstvo - od kraja druge-treće, do kraja šeste-sedme godine (Brković 2011, 135). ${ }^{1}$ U cilju razmatranja vaspitnoobrazovne uloge uspavanke značajno je ukazati na karakteristike čulne osetljivosti i opažanja, učenja i pamćenja, govora i mišljenja u okviru svakog od perioda ranog razvoja.

Dete reaguje na zvuk od samog rođenja, a već od drugog, trećeg meseca može lokalizovati i izvor zvuka. Tokom prvog detinjstva formira govorni ili fonematički sluh i muzički ili sluh za razlikovanje visina (Brković 2011, 157). Govorni sluh razvija se krajem prve i početkom druge godine, ritam i tempo kao elementi muzičkog sluha razlikuju se od treće godine, dok se od pete godine javlja preciznije razlikovanje visina i melodije, pri čemu je još uvek superiornije razlikovanje ritma i tempa. $U$ periodu ranog detinjstva dete ra-

\footnotetext{
${ }^{1}$ "Standardi za razvoj i učenje dece ranih uzrasta u Srbiji« period od rođenja do šeste godine uzrasne granice razvojnih faza definišu na sledeći način: o-8 meseci, 8-18 meseci, 18-36 meseci, 36-72 meseca (Baucal 2012).
} 
zlikuje i prepoznaje zvuke i glasove. Složeniji saznajni procesi javljaju se od osmog meseca, dok osnovni oblik učenja predstavlja uslovljavanje. U drugoj godini, u igri uloga deca primenjuju imitaciju, zatim opservaciono učenje, a započinje i poistovećivanje sa modelom - osobom za koju je dete afektivno vezano. Do sedme godine uspešnije je spontano nego voljno pamćenje, dok se u sedmoj godini razvijaju tehnike zapamćivanja, pri čemu vodeću ulogu u procesu namernog pamćenja ima govor, radi uspostavljanja smisaonih veza.

Tokom prve godine dete razume govor odraslih i može ga oponašati. Kvalitativne promene u domenu kognitivnog razvoja uopšte dešavaju se u drugoj godini, kada počinje lingvistička faza razvoja govora, odnosno kada se javlja prva reč koja ima značenje i koja izražava neko emocionalno stanje deteta, a u domenu intelektualnog razvoja započinje period razvoja inteligencije koja koristi simbole, pre svega verbalne. U procesu prelaska sa praktičnosituacione komunikacije na jezički sistem dete otkriva jezički kod, što mu odrasli olakšavaju prilagođavanjem verbalne komunikacije njegovim saznajnim mogućnostima (Brković 2011, 162). U domenu razvoja mišljenja, u periodu ranog detinjstva razvija se opažajno-praktično i simboličko mišljenje.

Emocionalni razvoj zasniva se na sistemu afektivnog vezivanja i afektivnoj komunikaciji. Afektivna vezanost koja se određuje kao bliska emocionalna veza roditelja i deteta inicirana primarnom potrebom (Harlow 1961; Ainsworth, Blehar i Waters 1978; Zazo 1980 prema Brković 2011), nastaje tokom prvih šest meseci, kao posledica interakcije deteta i roditelja, a u cilju obezbeđivanja blizine i zaštite odrasle osobe. Pri prelasku sa praktičnosituacione na znakovnu komunikaciju važan elemenat jeste gestovna komunikacija, koja se ispoljava kao potreba za saradnjom u zajedničkoj aktivnosti (nege, hranjenja, uspavljivanja, igre) i koja ima posredujuću ulogu, kao i intelektualna, a ne samo emocionalna značenja. U procesu komunikacije u periodu prvog detinjstva razvija se odnos sa drugima i empatija. Razumevanje gledišta ili pozicije drugog, njegovih emocija, misli, motiva i namera može se podsticati vaspitanjem, odnosno tumačenjem osećanja drugih. U periodu ranog detinjstva dete prepoznaje svoje emocije ljubavi, sreće, besa, razočaranja, stida, zavisti, ponosa, kao i prva estetska osećanja. Na ovom uzrastu pojavljuje se i dečije prosocijalno ponašanje, koje uključuje dalje razvijanje empatije.

Sa rođenjem počinje socijalni razvoj deteta, koji se takođe zasniva na afektivnoj vezanosti između dece i bliskih odraslih, a komunikacija sa neposrednim okruženjem u celini je socijalno posredovana. Proces prelaska sa praktično-situacione komunikacije u toku zajedničkih aktivnosti na znakovnu komunikaciju u ranom razvoju počiva na primarnoj socijalnosti deteta, 
koje izgrađuje čvrste socijalno-afektivne odnose sa odraslima i kod koga se rano formira sistem afektivne komunikacije (Ivić 1978). U prvom detinjstvu razvijaju se afektivna i gestovna, a tokom ranog detinjstva dominiraju saznajna i socijalna komunikacija.

Imajući u vidu multifunkcionalnost uspavanki u kontekstu različitih aspekata razvoja ličnosti deteta, sa jedne, i njegovih razvojnih osobenosti, sa druge strane, ispitivali smo kako vaspitač, čija je uloga od presudne važnosti u vaspitnoobrazovnoj praksi, percipira značaj ove književne forme u funkciji razvoja deteta.

\section{Metodološke osnove}

Pitanje potencijala uspavanke kao »književnog i kulturnog blaga« (Kleut 1997, 7) u funkciji vaspitanja i obrazovanja dece predškolskog uzrasta predstavlja istraživački problem. Predmet istraživanja jesu mogućnosti primene uspavanke u funkciji pojedinih aspekata razvoja, u aktivnostima sa predškolcima različitog uzrasta. Cilj je bio da se utvrdi da li i na koji način stručna sprema i radni staž vaspitača utiču na njihova iskustva i stavove u vezi sa funkcijom uspavanke u vaspitnoobrazovnom radu, što može doprineti unapređivanju metodičkog modela primene ove književne forme. Zadaci istraživanja odnosili su se na ispitivanje iskustava i stavova vaspitača u vezi sa: (a) ulogom uspavanke $u$ aktivnostima sa decom predškolskog uzrasta; (b) primerenošću primene uspavanke različitim predškolskim uzrasnim grupama dece.

Podaci za istraživanje dobijeni su anketiranjem vaspitača, koje je sprovedeno u aprilu i maju 2019. godine. Iz populacije zaposlenih u predškolskim ustanovama u Republici Srbiji tokom školske 2018/2019. godine odabran je uzorak od 302 vaspitača, iz sedam predškolskih ustanova u Gradu Beogradu, Zlatiborskom, Moravičkom, Kolubarskom, Mačvanskom, Rasinskom i Pčinjskom upravnom okrugu. Kao nezavisne varijable operacionalizovani su: stručna sprema vaspitača (srednja, viša, visoka) i iskustvo u radu sa predškolskom decom (do 10 godina, od 11 do 20 godina, od 21 do 30 godina, više od 30 godina).

Dobijeni podaci obrađeni su kvalitativno i kvantitativno - primenom statističkog softverskog paketa IBM SPSS Statistic 20, a razlike u iskustvu i stavovima vaspitača prema nezavisnim varijablama testirane su hi-kvadrat testom.

\section{Uspavanka u aktivnostima sa decom predškolskog uzrasta Uloga uspavanke}

Ulogu uspavanke u vaspitnoobrazovnom kontekstu istraživači određuju prema njenom doprinosu razvoju govora, zatim socioemocionalnom i sa- 
Tabela 1 Mišljenja vaspitača o ulozi uspavanke u vaspitnoobrazovnom radu sa decom u zavisnosti od stručne spreme

\begin{tabular}{|c|c|c|c|c|c|c|c|c|c|c|c|c|}
\hline \multirow{2}{*}{$\begin{array}{l}\text { Stručna } \\
\text { sprema }\end{array}$} & \multicolumn{2}{|c|}{ (1) } & \multicolumn{2}{|c|}{ (2) } & \multicolumn{2}{|c|}{ (3) } & \multicolumn{2}{|c|}{ (4) } & \multicolumn{2}{|c|}{ (5) } & \multicolumn{2}{|c|}{ (6) } \\
\hline & $n$ & $\%$ & $n$ & $\%$ & $n$ & $\%$ & $n$ & $\%$ & $n$ & $\%$ & $n$ & $\%$ \\
\hline Srednja & 8 & 36,4 & 3 & 13,6 & 5 & 22,7 & 5 & 22,7 & 1 & 4,5 & 22 & 100,0 \\
\hline Viša & 39 & 24,1 & 62 & 38,3 & 42 & 25,9 & 12 & 7,4 & 7 & 4,3 & 162 & 100,0 \\
\hline Visoka & 17 & 14,4 & 51 & 43,2 & 30 & 25,4 & 12 & 10,2 & 8 & 6,8 & 118 & 100,0 \\
\hline Ukupno & 64 & 21,2 & 116 & 38,4 & 77 & 25,5 & 29 & 9,6 & 16 & 5,3 & 302 & 100,0 \\
\hline
\end{tabular}

Primedbe (1) razvoj govora i jezičko stvaralaštvo, (2) socioemocionalni razvoj, (3) uspavljivanje, (4) kognitivni razvoj, (5) ostalo, (6) ukupno. $\chi_{2}=15,496, d f=8, p=0,050$.

znajnom razvoju, kao i upoznavanju i očuvanju kulturnog nasleđa (Kaya i Özkut 2016). Prvi istraživački zadatak odnosio se na ispitivanje mišljenja vaspitača o ulozi uspavanke u aktivnostima sa decom predškolskog uzrasta. Najveći procenat anketiranih navodi da u aktivnostima sa predškolcima ova književna forma doprinosi socioemocionalnom razvoju (38,4\%), četvrtina vaspitača ( $25,5 \%)$ navodi ulogu uspavanke u funkciji uspavljivanja, a petina $(21,2 \%)$ ukazuje na važnost uspavanke za razvoj govora i unapređivanje jezičkog stvaralaštva, dok 9,6\% ispitanika ističe kognitivni razvoj u kontekstu značaja uspavanke u vaspitnoobrazovnom radu (tabela 1). Mogućnost da dopune listu ponuđenih uloga uspavanke $u$ aktivnostima sa decom iskoristilo je 5,3\% vaspitača, od kojih polovina ističe da ne koriste ovu književnu formu u radu, dok ostali navode razvijanje muzičkih sposobnosti (sluha, osećaja za ritam i melodiju, muzičkog pamćenja), zatim upoznavanje sa narodnim stvaralaštvom i negovanje tradicije, kao i podsticanje upoznavanja različitih kultura i razvijanje interkulturalnosti.

Dobijeni rezultati u izvesnoj meri usaglašeni su sa nalazima ispitivanja mišljenja vaspitača u vezi sa ciljem primene uspavanke $u$ aktivnostima sa decom predškolskog uzrasta, prema kojima kao najznačajnije argumente za izbor ove književne forme vaspitači navode: socioemocionalni razvoj $\left(83,1 \%{ }^{2}\right.$ anketiranih), zatim uspavljivanje (49,3\%), kognitivni razvoj $(32,5 \%)$, razvoj govora i usvajanje jezika (30,1\%), razvijanje muzičkih sposobnosti (12,6\%), upoznavanje narodnog stvaralaštva i negovanje tradicije (5,3\%) (Purić i Kostić 2019, 362-364). Teorijski i empirijski rezultati drugih istraživanja takođe potvrđuju doprinos uspavanke socioemocionalnom razvoju (Güneş i Güneş 2012; Emeksiz 2011; Kasapoğlu Akyol 2017; Kaya i Özkut 2016). Pored iskaziva-

\footnotetext{
${ }^{2}$ Procenat je računat u odnosu na ukupan broj anketiranih, pri čemu su u pitanju otvorenog tipa vaspitači navodili više argumenata u prilog primeni uspavanke u radu sa decom.
} 
Tabela 2 Mišljenja vaspitača o ulozi uspavanke u vaspitnoobrazovnom radu u zavisnosti od radnog iskustva

\begin{tabular}{|c|c|c|c|c|c|c|c|c|c|c|c|c|}
\hline \multirow{2}{*}{$\begin{array}{l}\text { Radno } \\
\text { iskustvo }\end{array}$} & \multicolumn{2}{|c|}{ (1) } & \multicolumn{2}{|c|}{ (2) } & \multicolumn{2}{|c|}{ (3) } & \multicolumn{2}{|c|}{ (4) } & \multicolumn{2}{|c|}{ (5) } & \multicolumn{2}{|c|}{ (6) } \\
\hline & $n$ & $\%$ & $n$ & $\%$ & $n$ & $\%$ & $n$ & $\%$ & $n$ & $\%$ & $n$ & $\%$ \\
\hline $0-10$ & 15 & 16,7 & 38 & 42,2 & 28 & 31,1 & 7 & 7,8 & 2 & 2,2 & 90 & 100,0 \\
\hline $11-20$ & 20 & 18,7 & 45 & 42,1 & 24 & 22,4 & 10 & 9,3 & 8 & 7,5 & 107 & 100,0 \\
\hline $21-30$ & 14 & 23,7 & 22 & 37,3 & 15 & 25,4 & 6 & 10,2 & 2 & 3,4 & 59 & 100,0 \\
\hline Više od 30 & 15 & 32,6 & 11 & 23,9 & 10 & 21,7 & 6 & 13,0 & 4 & 8,7 & 46 & 100,0 \\
\hline Ukupno & 64 & 21,2 & 116 & 38,4 & 77 & 25,5 & 29 & 9,6 & 16 & 5,3 & 302 & 100,0 \\
\hline
\end{tabular}

Primedbe (1) razvoj govora i jezičko stvaralaštvo, (2) socioemocionalni razvoj, (3) uspavljivanje, (4) kognitivni razvoj, (5) ostalo, (6) ukupno. $\chi_{2}=14,083, d f=12, p=0,295$.

nja topline i nežnosti, brige i naklonosti, uspavanke su kao »zaštitni pokrivač«, koji štiti dete od spoljašnjeg, nepoznatog sveta, daje im osećaj sigurnosti i samopouzdanja. Ova književna forma određuje se i kao »blago socijalnih i kulturnih kodova« (Kaya i Özkut 2016, 163), posredstvom koga se, u razmeni između deteta i odraslih, kao i između deteta i druge dece, od generacije do generacije, konstruiše i rekonstruiše kultura (Pavlović Brenesalović 2012, 133).

Ispitivanje razlika u mišljenju vaspitača različite stručne spreme pokazuje tendenciju opadanja procenta anketiranih koji ukazuju na značaj uspavanke za razvoj govora i unapređivanje jezičkog stvaralaštva, i porasta procenta ispitanika koji apostrofiraju ulogu ove književne vrste u socioemocionalnom razvoju, sa porastom obrazovnog nivoa. Testiranjem uočenih razlika u mišljenju vaspitača nije potvrđena njihova statistička značajnost $\left(\chi^{2}=15,496, d f=\right.$ $8 ; p=0,050$ ), jer je dobijena vrednost hi-kvadrata manja od granične vrednosti $(15,507)$ na nivou značajnosti 0,050 (tabela 1).

Vaspitači sa najviše iskustva u radu sa decom u većoj meri ističu ulogu uspavanke u funkciji razvoja govora i podsticanja jezičkog stvaralaštva (32,6\%), za razliku od ostalih podgrupa anketiranih, formiranih prema radnom stažu (tabela 2). Prema statističkim pokazateljima, na mišljenje vaspitača o ulozi uspavanke u vaspitnoobrazovnom radu sa decom ne utiče značajno radno iskustvo kao nezavisna varijabla $\left(\chi^{2}=14,083 ; d f=12 ; p=0,295\right)$.

\section{Primerenost primene uspavanke različitim uzrasnim grupama}

U okviru drugog istraživačkog zadatka ispitivana su mišljenja vaspitača u vezi sa primerenošću primene uspavanke predškolskoj uzrasnoj grupi. Skoro polovina vaspitača $(45,0 \%)$ smatra da primena uspavanke odgovara mlađoj predškolskoj grupi (3-4 godine), a nešto manje od petine anketiranih (18,5\%) mišljenja je da je primena ove književne forme najprimerenija jaslenoj grupi 
Tabela 3 Mišljenja vaspitača o primerenosti primene uspavanke u predškolskoj uzrasnoj grupi, u zavisnosti od stručne spreme

\begin{tabular}{|c|c|c|c|c|c|c|c|c|c|c|c|c|}
\hline \multirow{2}{*}{$\begin{array}{l}\text { Stručna } \\
\text { sprema }\end{array}$} & \multicolumn{2}{|c|}{ (1) } & \multicolumn{2}{|c|}{ (2) } & \multicolumn{2}{|c|}{ (3) } & \multicolumn{2}{|c|}{ (4) } & \multicolumn{2}{|c|}{ (5) } & \multicolumn{2}{|c|}{ (6) } \\
\hline & $n$ & $\overline{\%}$ & $n$ & $\%$ & $n$ & $\%$ & $n$ & $\%$ & $n$ & $\%$ & $n$ & $\%$ \\
\hline Srednja & 4 & 18,2 & 4 & 18,2 & 6 & 27,3 & 8 & 36,4 & 0 & 0,0 & 22 & 100,0 \\
\hline Viša & 36 & 22,2 & 67 & 41,4 & 14 & 8,6 & 26 & 16,0 & 19 & 11,7 & 162 & 100,0 \\
\hline Visoka & 16 & 13,6 & 65 & 55,1 & 13 & 11,0 & 12 & 10,2 & 12 & 10,2 & 118 & 100,0 \\
\hline Ukupno & 56 & 18,5 & 136 & 45,0 & 33 & 10,9 & 46 & 15,2 & 31 & 10,3 & 302 & 100,0 \\
\hline
\end{tabular}

Primedbe (1) jaslena, (2) mlađa, (3) srednja, (4) starija, (5) pripremna, (6) ukupno. $\chi_{2}=26,678$, $d f=8, p=0,001$.

Tabela 4 Mišljenja vaspitača o primerenosti primene uspavanke predškolskoj uzrasnoj grupi, u zavisnosti od radnog iskustva

\begin{tabular}{|c|c|c|c|c|c|c|c|c|c|c|c|c|}
\hline \multirow{2}{*}{$\begin{array}{l}\text { Radno } \\
\text { iskustvo }\end{array}$} & \multicolumn{2}{|c|}{ (1) } & \multicolumn{2}{|c|}{ (2) } & \multicolumn{2}{|c|}{ (3) } & \multicolumn{2}{|c|}{ (4) } & \multicolumn{2}{|c|}{ (5) } & \multicolumn{2}{|c|}{ (6) } \\
\hline & $n$ & $\%$ & $n$ & $\%$ & $n$ & $\%$ & $n$ & $\%$ & $n$ & $\%$ & $n$ & $\%$ \\
\hline $0-10$ & 16 & 17,8 & 40 & 44,4 & 8 & 8,9 & 11 & 12,2 & 15 & 16,7 & 90 & 100,0 \\
\hline $11-20$ & 17 & 15,9 & 54 & 55,5 & 11 & 10,3 & 14 & 13,1 & 11 & 10,3 & 107 & 100,0 \\
\hline $21-30$ & 17 & 28,8 & 22 & 37,3 & 9 & 15,3 & 10 & 16,9 & 1 & 1,7 & 59 & 100,0 \\
\hline Više od 30 & 6 & 13,0 & 20 & 43,5 & 5 & 10,9 & 11 & 23,9 & 4 & 8,7 & 46 & 100,0 \\
\hline Ukupno & 56 & 18,5 & 136 & 45,0 & 33 & 10,9 & 46 & 15,2 & 31 & 10,3 & 302 & 100,0 \\
\hline
\end{tabular}

Primedbe (1) jaslena, (2) mlađa, (3) srednja, (4) starija, (5) pripremna, (6) ukupno. $\chi_{2}=18,630$, $d f=12, p=0,098$.

(tabela 3). Dobijeni rezultati mogu se objasniti činjenicom da deca od treće godine razlikuju ritam i tempo, a ritmičnost predstavlja ne samo jednu od osnovnih karakteristika uspavanke, već i osobenost fizičke strukture čoveka i prirode uopšte (Kasapoğlu Akyol 2017). Vaspitači sa srednjom stručnom spremom mišljenja su da primerenost primene uspavanke opada sa uzrastom dece, za razliku od anketiranih sa višim nivoom obrazovanja, koji smatraju da primena uspavanke u vaspitnoobrazovnom radu najviše odgovara hronološkom uzrastu između treće i četvrte godine (tabela 3$)$. Statistička analiza ( $\chi^{2}$ $=26,678 ; d f=8 ; p=0,001$ ) potvrđuje značajnost uticaja obrazovnog nivoa vaspitača na njihovo mišljenje o primerenosti primene uspavanke predškolskoj uzrasnoj grupi.

Mišljenja vaspitača o pogodnosti uspavanke za aktivnosti sa decom različitog uzrasta razlikuju se i u zavisnosti od njihovog radnog iskustva (tabela 4). Više od polovine anketiranih koji imaju između 11 i 20 godina radnog iskustva $(55,5 \%)$ smatra da je uspavanka najprimerenija mlađoj uzrasnoj grupi, dok je nešto više od četvrtine vaspitača sa iskustvom između 21 i 30 godina $(28,8 \%)$ mišljenja da je ovu književnu formu najbolje primenjivati u radu sa decom 
jaslenog uzrasta. Navedene razlike nisu statistički značajne $\left(\chi^{2}=18,630 ; d f=\right.$ $12 ; p=0,098)$.

\title{
Potencijal uspavanke u funkciji pojedinih aspekata razvoja dece različitih uzrasnih grupa
}

Anketirani vaspitači ističu smirujuću i opuštajuću ulogu uspavanki u aktivnostima sa decom predškolskog uzrasta, što korespondira sa prvobitnom namenom ove književne forme. Uspavanke su najčešće pevane u prvom licu, pored dečje kolevke, čime je uslovljena i njihova sugestivnost i emotivni angažman. Učestalost prisvojne zamenica za prvo lice i etičkog dativa prvog lica jednine (»Čuvaj, sanko, Jova mog?«»Čuj đe mi te sanko zove?«) implicira intimnu porodičnu atmosferu, osećaj sigurnosti i neposrednost koja je naročito bliska i svojstvena deci.

Uspavanka kao jedan od prvih modela maternjeg jezika dostupnih detetu (Nandakumara 2016) doprinosi razvoju govora i usvajanju jezika. Jezik uspavanki je jednostavan i melodičan, zbog čega ga deca brzo shvataju i uče (Güneş i Güneş 2012, 317). Bliskost koju dete uspostavlja sa izvođačem uspavanke i pažnja koja se usmerava na tekst pesme preduslovi su i za rađanje posebnog odnosa prema maternjem jeziku. Posredstvom ovih pesama dete ovladava artikulaciono-akustičkim osnovama jezika, pre svega ritmom, melodijom i akcentom (Hüsler 2011). Izrazita eufoničnost i dominacija zvučnih figura (asonance, aliteracije i onomatopeje) u ovim pesmama pogodne su (funkcionalne) za razvijanje pravilne artikulacije (Karanović 2005, 39):

\author{
Vozi baka troja kola sanka, \\ kupuje ih zlato Milke majka: \\ »Pošto, bako, troja kola sanka?« \\ »Troja kola, četiri dukata.« \\ Kupi majka troja kola sanka, \\ te ih Milki pod glavicu meće.
}

Vaspitači prepoznaju značaj ovog književnog teksta kao modela za podsticanje kreativnosti i govornog stvaralaštva. Uspavanke predstavljaju resurs koji u značajnoj meri može doprineti bogaćenju jezičke percepcije, razumevanja i produkcije kod dece (Nandakumara 2016). To je naročito uočljivo u imitativnim dečjim igrama, u kojima dolazi do »inverzije postupanja«, kada dete zauzima poziciju odraslih (majke) i peva uspavanku (Šarančić Čutura 2017, 57). Ono može, na primer, da nastupi kao majčina zamena (J. Jovanović Zmaj: »Kako sestra peva kad malog bracu ljulja«) ili da ispeva uspavanku 
igrački, kućnom ljubimcu, članu porodice i sl. Pored razvijanja empatije i mašte, ove igre podstiču kognitivni razvoj i poboljšavaju komunikativne veštine dece.

Melodičnost i ritmičnost uspavanki umnogome doprinose razvijanju muzičkih sposobnosti dece, pre svega razvijanju osećaja za ritam i melodiju, što je istaklo osam anketiranih vaspitača. Na osnovu rezultata dobijenih u ranijem istraživanju (Kostić i Purić 2020), preko $70 \%$ anketiranih vaspitača naglasilo je da u aktivnostima sa decom koristi uspavanke koje imaju muzičku pratnju. Muzika je veoma važna za duševno zdravlje svakog čoveka. Ona »utiče na ljudska bića emocionalno i duhovno«, a kod dece izaziva osećaj zadovoljstva i »optimalno funkcionisanje mozga« (Vlainić i Jovančević 2009, 25), te reguliše emocije, razmišljanje i učenje. Muzika poboljšava veštinu slušanja i razvija pažnju, stimuliše razvoj govora i bogati rečnik, podstiče emocionalne i kreativne reakcije i pamćenje. $S$ tim u vezi posebno značajnu ulogu imaju uspavanke i druge ritmičke pesme, pri čijem se pevanju postavljaju osnove za razvoj »dugoročnog pamćenja« (Carlton 2001).

Promišljajući o ulogama uspavanki, svega jedan anketirani vaspitač istakao je potencijal ovog žanra za uspostavljanje interkulturalnog dijaloga. $U$ fokusu je, s tim u vezi, imao uspavanke na romskom jeziku i njihovu ulogu u »upoznavanju i prihvatanju sličnosti i razlika među decom druge nacionalnosti«. »Različiti aspekti kulture se odražavaju u jeziku«, a jezik, s druge strane, »doprinosi njihovom izdvajanju, definisanju i prihvatanju unutar šireg kolektiva« (Bugarski 2005, 20). Otuda je veoma važno u ranom učenju jezika razvijati kod deteta svest o tome »da postoje mnogi jezici i kulture« osim maternje (BilićŠtefan 2008, 233), te da »nijedna kultura sama po sebi nije ni bolja ni lošija od drugih« (Petrović 2006).

Interkulturalne kompetencije se stiču, nisu urođene, dakle, ne razvijaju se intuitivno. Da bi se pored vlastite kulture razumela i druga kultura, neophodna je podrška i vaspitno-obrazovnih ustanova. Upoznavanjem drugih kultura, razvija se poštovanje prema kulturnim različitostima, što značajno pomaže u prevazilaženju predrasuda, stereotipa i etnocentrizma. Vaspitači bi, dakle, mogli da imaju veliku ulogu u postavljanju osnova za razvoj interkulturalnih veština dece.

Veliki broj uspavanki raznih naroda, sakupljenih u antologiji San u pidžami (Đurišić 1986) potvrđuje svrsishodnost podsticanja interkulturalnosti posredstvom uspavanki. Reč je o pesmama koje su svojom tematskom, leksičkom i gramatičkom građom primerene uzrastu dece od tri do sedam godina. Odgovarajuća metodička obrada usmerila bi pažnju dece-recipijenata na određene sadržaje. Upoznavanje sa usmenim uspavankama vlastitog naroda po- 
moglo bi im u stvaranju predstave o etnokulturološkim osobenostima svog naroda i principima na kojima je počivala tradicionalna zajednica (pravila ponašanja, hijerarhija u porodici, podela poslova i sl.). Istovremeno, usmene uspavanke drugih naroda pružaju deci sadržaje koji osvetljavaju mnoge specifičnosti života tih naroda - antroponomastiku (tipska imena koja se razlikuju od onih karakterističnih za srpske usmene uspavanke, na primer, Vanja u ruskim narodnim uspavankama), običaje (očevi, na primer, odlaze u lov da bi nabavili hranu), gastronomiju (namirnice karakteristične za određeno podneblje), svakodnevicu (apostrofiranje životinja tipičnih za regiju koju naseljava određeni narod - na primer, hijena i slon u sudanskoj narodnoj uspavanki; tuljan, pingvin i irvas u islandskoj uspavanki, sova u indijanskoj itd.), društvene konvencije, ali i one na kojima su neretko zasnovane predrasude i razni oblici diskriminacije - boja kože i sl. Posebno su, s tim u vezi, funkcionalne romske uspavanke, koje u sebi kriju neke od etnokulturoloških posebnosti ovog naroda (život u čergi), ali i metafore kojima se obesmišljava bilo kakva diskriminišuća insinuacija (Đurišić 1986, 13):

Dok ne pukne zora rana, nad kolevkom bdije mama:

čuva tvoje toplo gnezdo.

Spavaj, spavaj, crna zvezdo!

Okrilje u kome romsko dete odrasta, pre svega ljubav i nežnost kojom ga majka štiti, istovetno je onome u kome odrastaju i druga deca, što može da bude povod za postavljanje osnova na kojima će se zasnivati dobra komunikacija sa pripadnicima nacionalnih manjina u budućnosti. Sličan primer uočava se i u kineskoj narodnoj uspavanci (Đurišić 1986, 31):

Sine žuti i bucmasti,

jedi riže pa mi rasti.

Pominjanje boje kože i namirnice koja čini osnovu kineske kuhinje može biti uvod u upoznavanje i uvažavanje specifičnosti drugih naroda. Deca predškolskog uzrasta neće moći da razumeju većinu pomenutih osobenosti jednog kulturološkog entiteta, stoga im je potrebna i podrška vaspitača kako bi se sve što je neobično i nepoznato povezalo u skladan sistem u okviru određenog društvenog i socijalnog konteksta (Hofmann 2006).

Uočavanje različitosti i poštovanje različitosti preduslov su za »razvijanje pozitivnih osećanja prema drugima", "podsticanje zajedništva i brige za druge«, »razvijanja pozitivnih osobina ličnosti - nežnosti i saosećanja«, 
čemu, prema mišljenju 11 anketiranih vaspitača, može doprineti korišćenje uspavanki u aktivnostima sa decom.

S tim u vezi, uspavanke mogu biti i predložak za upoznavanje sa narodnim tradicijom i usmenom književnošću, što je bilo mišljenje pet anketiranih vaspitača. Kroz uspavanke se detetu "prenosilo iskustvo zajednice« (Prstojević 2012,68$)$ i sugerisala mu se pravila ponašanja. Jedan anketirani vaspitač iznosi da ih koristi pri obradi teme »Porodica - kako je bilo nekada, a kako sad«. Usmene uspavanke su višestruko funkcionalne za ukazivanje na specifičnosti tradicionalne patrijarhalne porodice i osoben sociokulturološki kontekst kome je pripadala. Najčešće su ih izvodile majke, ređe neka druga ženska osoba iz porodice (sestra ili baba). U najvećem broju zapisanih uspavanki apostrofira se muško dete, što ukazuje (ili potvrđuje) da je primarno mesto u zajednici zauzimao muškarac (up. Pešikan Ljuštanović 2012a), kome se, u anticipiranju budućnosti (Pešikan Ljuštanović 2012b), namenjivalo da zauzme neku značajnu ulogu u društvu, da bude snažan, hrabar i majčin pomoćnik i zaštitnik, dok se ženskoj deci želelo da dorastu do udaje. U autorskim uspavankama menja se perspektiva - uvodi se i žensko dete, a značajnu ulogu u obezbeđivanju mirnog sna ima i otac (Milivojevic 2016):

Spavaj, spavaj, bebo ti, mama će ti pevati, spavaj, spavaj, bebo ti, tata će te ljuljati.

Novi poetski elementi, koje uvodi autorska uspavanka, pre svega »očinski diskurs nežnosti« (Živković 2019, 611), pogodne su za razgovor o fukcionisanju porodice u prošlosti i u savremenom trenutku. Uočavanje sličnosti i razlika između dva vremena i dva porodična modela podrška je i razvoju kritičkog mišljenja kod dece na ranom uzrastu (Steele et al. 2002).

\section{Zaključak}

Uspavanka je granično područje između književnosti i folklora, sinkretički žanr koji povezuje jezičke, muzičke, psihološke i kulturne aspekte (Jeziorkowska-Polakowska 2010). Primena ove vrste književnog sadržaja u vaspitnoobrazovnom radu može omogućiti deci predškolskog uzrasta da upoznaju, istražuju i preispituju specifične kulturne kodove i etno-folklorne koncepte (Kasapoğlu Akyol 2017, 171-172), čime se obezbeđuje kontinuitet društvenog i kulturnog života. Ostvarivanje ovog kompleksnog zadatka u značajnoj meri zavisi od vaspitača, od njegovih znanja, umenja i uverenja. 
Rezultati ispitivanja uloge uspavanke u vaspitnoobrazovnom kontesktu pokazuju da vaspitači u najvećoj meri prepoznaju doprinos ove književne vrste socioemocionalnom razvoju, zatim ističu njenu ulogu u funkciji umirivanja i uspavljivanja, a ukazuju i na važnost za razvoj govora i unapređivanje jezičkog stvaralaštva.

Saznajni razvoj, razvijanje muzičkih sposobnosti, upoznavanje sa narodnim stvaralaštvom i negovanje tradicije, kao i razvijanje interkulturalnosti vaspitači takođe smatraju benefitima primene uspavanke u aktivnostima sa predškolskom decom. Pritom, skoro polovina anketiranih vaspitača $(45,0 \%)$ mišljenja je da je primena uspavanke najprimerenija u radu sa decom mlađe predškolske grupe. Na mišljenja vaspitača o ulozi uspavanke o vaspitnoobrazovnom radu ne utiče značajno stručna sprema, ni radno iskustvo. Na percepciju primerenosti primene uspavanke određenim predškolskim uzrasnim grupama utiče nivo obrazovanja vaspitača, ali ne i njihovo iskustvo u radu sa decom.

Razumevanje karakteristika i osobenosti razvoja dece na ranim uzrastima, kao i karakteristika svakog deteta kao posebne ličnosti (Pešikan i Antić 2012, 108) doprinosi njegovom uspešnom učenju, razvoju i dobrobiti, nezavisno od konkretnih odnosa i kontekstualnog iskustva kroz koje deca razvijaju i konstruišu razumevanje i znanje, očekivanja i veštine (Pavlović Brenesalović 2012, 133). Istraživački nalazi pokazuju da su vaspitači svesni značaja uspavanki u funkciji ostvarivanja vaspitnoobrazovnih ciljeva zasnovanih na teorijskovrednosnim postulatima detinjstva i deteta, što je jedan od preduslova obezbeđivanja kvalitetnog okruženja za rani razvoj i učenje.

\section{Zahvala}

Rad je nastao u okviru projekta »Nastava i učenje - problemi, ciljevi i perspektive« (br. 179026), koji podržava Ministarstvo prosvete, nauke i tehnološkog razvoja Republike Srbije.

\section{Bibliografija}

Ainsworth, M., M. Blehar i E. Waters. 1978. Patterns of Attachment. Hillsdale, NJ: Erlbaum.

Antoš, A. 1974. Osnove lingvističke stilistike. Zagreb: Školska knjiga.

Baucal, A. 2012. »Razvoj standarda za učenje i razvoj dece ranih uzrasta. U U Standardi za razvoj i učenje dece ranih uzrasta u Srbiji, ur. A. Baucal, 9-16. Beograd: Institut za psihologiju Filozofskog fakulteta Univerziteta u Beogradu i Unicef.

Bilić-Štefan, M. 2008. »Interkulturalna komunikacijska kompetencija u udžbenicima za engleski jezik u osnovnoj školi.« Odgojne znanosti 19 (1): 231-240. 
Brković, A. 2011. Razvojna psihologija. Čačak: Regionalni centar za profesionalni razvoj zaposlenih u obrazovanju.

Bugarski, R. 2005. Jezik i kultura. Beograd: Biblioteka XX vek.

Carlton, E. 2001. »Učenje kroz glazbu. "Dijete, vrtić, obitelj 25:23-24.

Čalenić, M. 1972. Seo car na kantar: narodna književnost za decu. Beograd: Naučna knjiga.

Čukovski, K. 1986. Od druge do pete. Beograd: Zavod za udžbenike i nastavna sredstva.

Đurišić, D. 1986. San u pidžami, antologija uspavanki. Novi Sad: Dnevnik.

Emeksiz, A. 2011. »Are Lullabies to Sleep?« Journal of Faculty of Letters, Trakya University 1 (2): 143-156.

Güneş, H., i N. Güneş. 2012. »The Effects of Lullabies on Children.«International Journal of Business and Social Science 3 (7): 316-321.

Harlow, H. 1961. »The Development of Affectional Patterns in Infant Monkeys." U Determinants of Infant Behaviour, ur. U. B. Foss, 75-97. London: Methuen.

Hofmann, M. 2006. Interkulturelle Literatur-wissenschaft: Eine Einführung. Padeborn: Fink.

Hüsler, S. 2011. Verse, Lieder und Reime - traditionelle sprachliche Bildung für die Kleinsten quer durch viele Sprachen. München: Deutsches Jugendinstitut.

Ivić, I. 1978. Čovek kao animal symbolicum. Beograd: Nolit.

Jeziorkowska-Polakowska, A. 2010. Songs Cast in Two Languages. Lublin: Wydawnictwo Towarzystwo Naukowe KUL.

Karanović, Z. 2005. Puna tepsija zlatnih kolačića: priručnik narodnog pesništva za decu, vaspitače i učitelje. Novi Sad: Platoneum.

Kasapoğlu Akyol, P. 2017. »From Tradition to the Future Universal Language of Love.« U Recent Developments in Arts, ur. B. Zbigniew, H. Arslan i M. A. Icbay, 159-169. International Association of Social Science Research.

Kaya, S. Ö., i B. Özkut. 2016. »The Influence of Developing Technology and Mother's Songs: Lullabies. « International Journal of Human Sciences 13 (1): 778786.

Kleut, M. 1997. »Dete - usmena kultura - masovna kultura.« Detinjstvo 3:5-7.

Kostić, Lj., i D. Purić. 2020. »Vaspitač i izbor uspavanki u aktivnostima sa decom predškolskog uzrasta.« Inovacije u nastavi 33 (4): 48-60.

Košprdić, M., i I. Damjanov. 2017. »O konceptu deteta nekad i sad - analiza govornih činova u narodnoj i savremenoj uspavanci.« Detinjstvo 43 (2): 72-84.

Krnjević, H. 1992. »Uspavanke.« U Rečnik književnih termina, ur. D. Živković, 907. Beograd: Nolit.

Lešić, Z. 2011. Jezik i književno delo. Beograd: Službeni glasnik.

Lotman, J. 1976. Struktura umetničkog teksta. Beograd: Nolit.

Milivojevic, T. 2016. »Tina Milivojevic - Uspavanka za malog batu.« Video na YouTubeu, 3:21. 2. august. https://www.youtube.com/watch?v=f1un7rlidaA.

Nandakumara, U. 2016. »Lullabies Enrich Child Linguistic Development.« https: 
//www.academia.edu/34634494/Lullabies_enrich_child_lingustic _development.

Noll, G. 2012. »Anmerkungen zu aktuellen Fragen des Wiegenliedes. «Ad marginem: Mitteilungen des Instituts für europäische Musikethnologie der Universität zu Köln 84:3-23.

Pavlović Brenesalović, D. 2012. »Odnosi na ranim uzrastima. U U Standardi za razvoj i učenje dece ranih uzrasta u Srbiji, ur. A. Baucal, 133-150. Beograd: Institut za psihologiju Filozofskog fakulteta Univerziteta u Beogradu i Unicef.

Pešikan Ljuštanović, Lj. 2012a. »Dete u usmenoj uspavanci - uzrasni ili obreni status?« U Gospođi Alisinoj desnoj nozi: ogledi o književnosti za decu, ur. Lj. Pešikan Ljuštanović, 7-19. Novi Sad: Međunarodni centar književnosti za decu Zmajeve dečje igre.

—_. 2012b. »Usmena uspavanka - uslovnost žanra." U Gospođi Alisinoj desnoj nozi: ogledi o književnosti za decu, ur. Lj. Pešikan Ljuštanović, 21-34. Novi Sad: Međunarodni centar književnosti za decu Zmajeve dečje igre.

Pešikan, A., i S. Antić. 2012. »Učenje i razvoj na ranim uzrastima.« U Standardi za razvoj i učenje dece ranih uzrasta u Srbiji, ur. A. Baucal, 85-112. Beograd: Institut za psihologiju Filozofskog fakulteta Univerziteta u Beogradu i Unicef.

Petrović, D. 2006. »Interkulturalno (ne)razumevanje.« U Uvod u mirovne studije 2, ur. D. Popadić, 67-78. Beograd: Grupa Most.

Pravilnik o osnovama programa predškolskog vaspitanja i obrazovanja. 2018. Službeni glasnik Republike Srbije - Prosvetni glasnik, br. 16. https://www .pravno-informacioni-sistem.rs/SIGlasnikPortal/eli/rep/pg/ministarstva/ pravilnik/2018/16/3/reg.

Prstojević, V. 2012. »Usmena uspavanka u književnom, socijalnom i obrednom kontekstu.« Zbornik radova Visoke škole strukovnih studija za obrazovanje vaspitača u Kikindi 7 (1): 63-79.

Purić, D., i Lj. Kostić. 2019. »Značaj primene uspavanki u aktivnostima sa predškolskom decom (iz ugla vaspitača). «U Nauka, nastava, učenje - problemi $i$ perspektive, ur. S. Marinković, 355-368. Užice: Pedagoški fakultet.

Steele, J., K. Meredith, C. Temple i S. Walter. 2002. Kritičko mišljenje na ranom uzrastu. Beograd: Centar za interaktivnu pedagogiju.

Šarančić Čutura, S. 2017. Folklorno u prostoru naivnog: usmena književnost u kontekstu književnosti za decu. Sombor: Pedagoški fakultet.

Vlainić, M., i M. Jovančević. 2009. »U ritmu djetinjstva.« Dijete, vrtić, obitelj: časopis za odgoj i naobrazbu predškolske djece namjenjen stručnjacima i roditeljima 15 (56): 25-27.

Zazo, R. 1980. Poreklo čovekove osećajnosti. Beograd: Zavod za udžbenike i nastavna sredstva.

Živković, D. 2019. »Stilske karakteristike uspavanke. «U Bebe, ur. D. Bošković i Č. Nikolić, 605-615. Kragujevac: Filološko-umetnički fakultet. 


\section{Perception of Lullabies' Role in the Development of Preschool Children from Pre-School Teachers' Point of View}

The lullaby as the content of educational activities at the preschool level can be a factor in the linguistic, cognitive, and socio-emotional development of the child. Bearing in mind the multiple functionality of this literary form in the context of different aspects of the child's personality development, as well as its developmental features, authors of the paper examine preschool teachers' opinions $(N=302)$ regarding (a) the role of lullabies in activities with preschool children; and (b) the appropriateness of applying lullabies to different preschool age groups of children. Survey results show that preschool teachers recognize the importance of lullabies in the function of socio-emotional development, speech and language development, cognitive development, improving musical abilities, nurturing tradition and developing interculturality, emphasizing that it is most appropriate in working with children from 3 to 4 years. Understanding the importance of this literary genre in the function of achieving educational goals based on the value postulates of childhood and child, by educators as coordinators of activities at the preschool level, contributes to providing a quality environment for early development and learning.

Keywords: Iullaby, preschool teacher, preschool child, emotional development, social development 